\title{
A potencialidade do uso de resíduo de borracha de pneu em argamassa: análise das propriedades físicas e mecânicas
}

\author{
The potentiality of the use of tire rubber residue in \\ mortar: analysis of physical and \\ mechanical properties
}

Mônica Navarini Kurz ${ }^{1}$, Tais Marini Brandelli ${ }^{2}$, Charlei Marcelo Paliga ${ }^{2}$, Ariela da Silva Torres ${ }^{2}$

\footnotetext{
${ }^{1}$ Faculdade de Arquitetura e Urbanismo - UFPel - Rua Benjamin Constant, n. 1359, Pelotas, RS, Brasil. e-mail: monicanavarini@yahoo.com.br

${ }^{2}$ Faculdade de Arquitetura e Urbanismo - UFPel - Rua Benjamin Constant, n. 1359, Pelotas, RS, Brasil. e-mail: taisbrandelli@hotmail.com; charlei.paliga@ufpel.edu.br; arielatorres@gmail.com
}

\section{RESUMO}

O setor da construção civil vem absorvendo resíduos de vários segmentos industriais e transformando-os em componentes para utilização nas construções, através da sua incorporação em materiais, como por exemplo em argamassas e concretos. Devido a este fato, o presente estudo tem o objetivo de avaliar o comportamento de argamassas com diferentes substituições de agregado miúdo por resíduo de borracha, conferindo seu comportamento físico e mecânico. Com a finalidade de verificar a melhor relação de substituição, os ensaios foram realizados em argamassa referência e em argamassas com resíduos nas proporções de 2,5\%, 5\%, 10\% e $15 \%$ de substituição de areia por borracha, possuindo, portanto quatro famílias de argamassas com resíduos de borracha, sendo o traço referência o 1:3 (cimento:agregado). Para confecção das argamassas, os agregados, areia e borracha, foram divididos em quatro frações granulométricas, gerando quatro subfamílias de argamassas para cada família de argamassa com resíduos. Para caracterização das argamassas foram realizados ensaios de índice de consistência, de compressão axial, de resistência à tração por compressão diametral, de absorção por capilaridade e de absorção por imersão. Com base nestes ensaios foram escolhidos dois traços de argamassa para revestirem dois protótipos de alvenaria, visando verificar o comportamento do revestimento. Os protótipos foram analisados visualmente em relação ao surgimento de manifestações patológicas e foram ensaiados quanto a absorção de água por meio do método cachimbo. Os resultados indicam que nas argamassas com resíduo ocorreu um decréscimo nas resistências. Nas absorções algumas subfamílias possuíram melhor desempenho que a argamassa referência. Para os protótipos a utilização de borracha não influenciou o comportamento do revestimento argamassado e a permeabilidade pelo método cachimbo se mostrou sem diferenças significativas quanto aos resultados obtidos.

Palavras-chave: Tecnologia da arquitetura, inovação da construção, resíduo de borracha, argamassa de revestimento.

\section{ABSTRACT}

The construction industry has been absorbing waste from various industrial segments and transforming them into components for use in construction, through its incorporation in materials such as mortars and concretes. Due to this fact, this study aims to evaluate the behavior of mortars with different substitutions of small aggregates for rubber residue, conferring their physical and mechanical behavior. In order to verify the best substitution ratio, the tests were carried out on reference mortar and mortar with residues in the proportions of 2,5\% wt, $5 \% w t, 10 \% w t$ and $15 \% w t$ of substitution of sand by rubber, the reference trace is 1: 3 (cement: aggregate). For the preparation of the mortars, the aggregates, sand and rubber were divided into four granulometric fractions, generating four subfamilies of mortars for each family of mortar with residues. For characterizing of the mortars, tests of consistency index, axial compression, tensile strength by diametrical compression, absorption by capillarity and absorption by immersion were performed. Based on these tests two 
traces of mortar were chosen to cover two prototypes of masonry, in order to verify the behavior of the coating mortar. The prototypes were analyzed visually in relation to the appearance of pathological manifestations and were tested for water absorption by the pipe method. The results indicate that in mortars with residue a decrease in the resistances has occurred. In the absorptions some subfamilies had better performance than the reference mortar. For the prototypes the use of rubber did not influence the behavior of the mortar coating and the permeability by the pipe method was shown without significant differences in the results obtained.

Keywords: Architecture technology, construction innovation, rubber residue, coating mortar.

\section{INTRODUÇ̃̃O}

O aumento da produção de veículos automotivos ocasionou o crescimento na quantidade de resíduo de borracha de pneu produzido. Conforme dados de 2015 [1], desde 1999, quando começou a coleta pelos fabricantes, 3,11 milhões de toneladas de pneus inservíveis foram coletados e destinados adequadamente, o equivalente a 623 milhões de pneus de passeio. LAGARINHOS E TENÓRIO [2] explanam que o que tem contribuído para o aumento de descarte de resíduos são o rápido desenvolvimento tecnológico, aumento da população e demanda por novas tecnologias. Diversos pesquisadores vêm investigando alternativas de reciclagem deste material, por se tratar de um resíduo de difícil absorção pelo meio ambiente [3].

No ano de 2015, no Brasil, uma das formas mais comuns de reaproveitamento dos pneus inservíveis foi como combustível alternativo para as indústrias de cimento. Mais recentemente, também vêm sendo utilizados como componentes para a fabricação de manta asfáltica e asfalto-borracha. Todas estas destinações são aprovadas pelo Instituto Brasileiro do Meio Ambiente e dos Recursos Naturais Renováveis (IBAMA) como destinações ambientalmente adequadas [1]. No Brasil, no ano de 2014, a porcentagem de cumprimento das metas de destinação final dos pneus foi de $97,60 \%$, sendo $66,90 \%$ do total destinado para a valorização energética e 33,10\% para a recuperação do material [4].

Com o aumento da conscientização da população pela preservação do meio ambiente e saúde pública, estudos vêm verificando a potencialidade de utilização de resíduos de borracha como agregado em argamassas e concretos. No qual representam um avanço para o setor de construção civil e para o meio ambiente, auxiliando a retirada dos resíduos da natureza e diminuindo a extração de materiais naturais para fabricação de produtos utilizados nas construções.

BEZERRA [5] afirma que os impactos causados pelo homem ao meio ambiente são uma preocupação constante, e por este motivo pesquisadores vêm estudando maneiras de proporcionar novos materiais ao mercado. Para tanto, deve-se procurar avançar em técnicas de reaproveitamento de materiais alternativos, como forma de atenuar os impactos ambientais causados pelos mesmos.

A construção civil, além de possuir um grande potencial de geração de resíduos, consome grandes quantidades dos recursos naturais não renováveis. Uma maneira de utilizar estes resíduos é incorporando-os em argamassas e/ou concretos, substituindo, parcial ou totalmente, um componente não (re)aproveitável ou renovável por resíduos [6]. No entanto, são muito importantes estudos dos usos e das propriedades destes materiais a fim de garantir viabilidade na sua utilização. Conforme MENEGUINI [7], para se obter um melhor desempenho no uso do resíduo de borracha em argamassas deve ocorrer a diminuição do tamanho das partículas de borracha, por meio de peneiramento do resíduo de borracha.

A reciclagem de resíduos é uma forma de contribuir com a preservação ambiental. Dentre os resíduos, cuja sua aplicabilidade em materiais de construção civil vem sendo estudada, encontra-se estudos com resíduos de pneus. A reutilização de pneus na construção civil, em suas várias formas, é muito viável devido sua alta durabilidade, por ser um material altamente elástico e ter a função de isolante devido à sua baixa condutividade térmica e sonora [8]. Sobre o uso de resíduos de pneus, cita-se alguns trabalhos que estudaram sua utilização em concretos, como os trabalhos de GUNEYISI et al. [9], MARTINS et al. [10] e CARNEIRO et al. [11]. Sobre o uso de resíduo de borracha de pneu em argamassas cita-se os trabalhos de MENEGUINI [7], TURATSINZE et al. [12], MARQUES et al. [13], PEDRO et al. [14], SALES E MENDES [6] e GUELMINEA et al. [15].

De acordo com a ABNT NBR 7200 [16], as argamassas são uma mistura homogênea, constituídas de aglomerante, agregado miúdo e água, podendo conter aditivos ou adições, que possuem capacidade de endurecimento e aderência.

SILVA [17] define as principais funções da argamassa como: unir componentes de alvenaria, regularizar a absorção da base ou melhorar a aderência, corrigir imperfeições da base, cobrir e regularizar a superfície da base, unir componentes do acabamento decorativo e dar acabamento final à superfície. Para o autor, as 
argamassas ainda possuem outras funções e particularidades como: aspecto estético, dificultar a infiltração de água na edificação e impedir o crescimento de micro-organismos.

De acordo com CARASECK [18], as argamassas de revestimento são utilizadas para revestir paredes, muros e tetos, os quais, geralmente, recebem acabamentos como pintura, revestimentos cerâmicos, laminados, entre outros. Entre as propriedades essenciais ao bom desempenho das argamassas de revestimento, estão: trabalhabilidade, especialmente consistência, plasticidade e adesão inicial; retração; aderência; permeabilidade à água; resistência mecânica, principalmente a superficial; capacidade de absorver deformações.

Sobre a utilização de resíduos em materiais, SOUZA [19] salienta que o produto com uso de material reciclado necessita satisfazer às solicitações a que será submetido e as recomendações previstas pelas normas da Associação Brasileira de Normas Técnicas (ABNT), devendo ser funcional para o usuário e para indústria da construção civil.

O presente estudo tem o objetivo de avaliar o comportamento de argamassas com diferentes substituições de agregado miúdo por resíduo de borracha. Para tanto realizou-se a comparação com uma argamassa de referência, analisando o comportamento físico e mecânico por meio de ensaios normatizados pela $\mathrm{ABNT}$ e de protótipos de alvenaria revestidos com as argamassas referências e com as duas argamassas com melhor desempenho nos ensaios.

\section{MATERIAIS E MÉTODOS}

O programa experimental se baseia em uma argamassa referência e uma argamassa com resíduo de borracha. O traço utilizado foi de uma argamassa de cimento e agregado miúdo, na proporção de 1:3, sendo baseado na norma brasileira ABNT NBR 7215 [20], que trata sobre resistência à compressão do cimento Portland.

As proporções de substituição de areia por resíduo de borracha foram de 2,5\%, 5\%, $10 \%$ e 15\%, visando verificar a influência do resíduo nas propriedades físicas e mecânicas da argamassa. SALES E MENDES [6] utilizaram as proporções de 5\% e 10\% de substituição de resíduo de borracha por areia em seu estudo sobre argamassas, porém neste trabalho optou-se por abranger outras duas substituições, com maior e menor porcentagem de substituição para se obter uma abrangência maior sobre o comportamento da argamassa com resíduo.

Para confecção das argamassas, os agregados, areia e borracha, foram divididos em quatro frações passantes nas peneiras granulométricas: 2,$00 ; 1,18 ; 0,600 ; 0,300 \mathrm{~mm}$. Com intuito de verificar a influência das diferentes frações da granulometria nas argamassas, as famílias de substituição de 2,5\%, 5\%, 10\% e $15 \%$ foram subdivididas em quatro subfamílias: subfamília 4 (substitui a proporção nas quatro frações de areia por borracha); 3 (substituição nas três frações mais finas); 2 (substituição nas duas frações mais finas); 1 (substituição somente na fração mais fina), conforme mostrado na Figura 1.

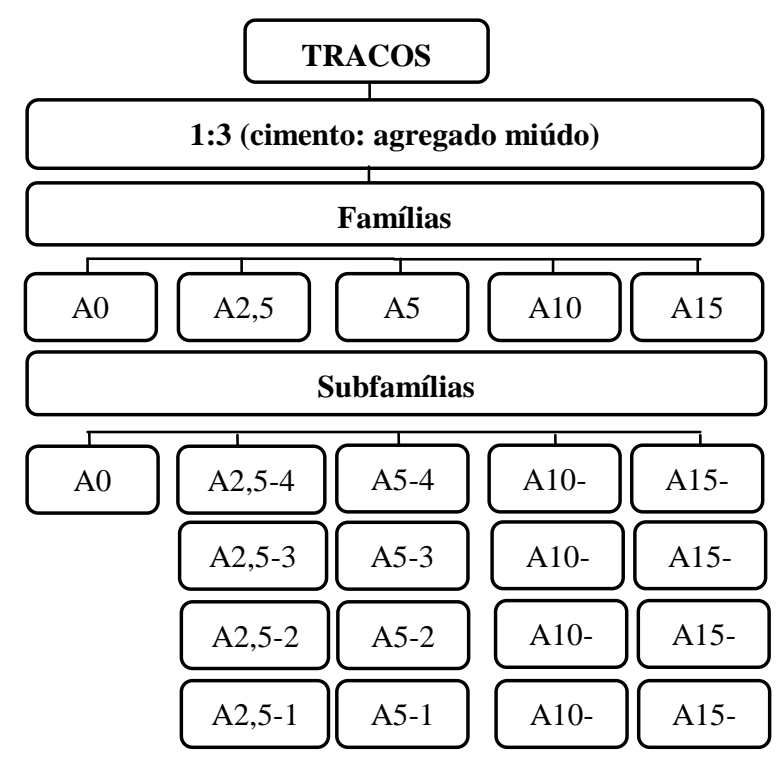

Figura 1: Fluxograma das famílias e subfamílias de argamassas.

Para o desenvolvimento desta pesquisa foi utilizado o cimento Portland CP IV-32, escolhido por ser 
um dos tipos mais empregados em obras de construção civil da região; água potável proveniente da rede de distribuição municipal, fornecida pela concessionária local (SANEP - Serviço Autônomo de Saneamento de Pelotas); areia quartzosa lavada, de granulometria média. O resíduo de borracha de pneu utilizado foi adquirido junto a uma reformadora de pneus localizada na cidade de Pelotas/RS. Este resíduo provém da banda de rodagem, por meio da recapagem dos pneus. Portanto, possui tanto o pó do resíduo, como partículas maiores em formato alongado.

A areia foi caracterizada por meio de ensaios em laboratório, de acordo com as normas vigentes da ABNT, sendo que os resultados estão apresentados na Tabela 1.

Tabela 1: Características físicas da areia.

\begin{tabular}{|c|c|c|}
\hline TIPO DE ENSAIO & \multicolumn{2}{|c|}{ RESULTADOS } \\
\hline \multirow{10}{*}{$\begin{array}{c}\text { Composição granulométrica } \\
\text { NBR NM } 248 \text { (ABNT, 2003) }\end{array}$} & Peneiras & Retido acumulado (\%) \\
\hline & 4,75 & 1,005 \\
\hline & 2,36 & 5,030 \\
\hline & 1,18 & 14,645 \\
\hline & 0,600 & 22,510 \\
\hline & 0,300 & 33,975 \\
\hline & 0,150 & 93,590 \\
\hline & Fundo & 99,415 \\
\hline & Ø máx (mm) & 2,36 \\
\hline & Módulo de Finura & 2,70 \\
\hline $\begin{array}{c}\text { Massa específica }\left(\mathrm{g} / \mathrm{cm}^{3}\right) \\
\text { NBR NM } 52(\mathrm{ABNT}, 2009)\end{array}$ & \multicolumn{2}{|c|}{2,63} \\
\hline $\begin{array}{l}\text { Massa unitária solta }\left(\mathrm{g} / \mathrm{cm}^{3}\right) \\
\text { NBR NM } 45(\mathrm{ABNT}, 2006)\end{array}$ & \multicolumn{2}{|c|}{1,46} \\
\hline $\begin{array}{c}\text { Índice de volume de vazios (\%) } \\
\text { NBR NM } 45 \text { (ABNT, 2006) }\end{array}$ & \multicolumn{2}{|c|}{44,49} \\
\hline $\begin{array}{c}\text { Absorção (\%) } \\
\text { NBR NM } 30 \text { (ABNT, 2001) }\end{array}$ & \multicolumn{2}{|c|}{6,88} \\
\hline
\end{tabular}

Conforme SANTOS [21], com a inexistência de normas para caracterização do resíduo de borracha, o mesmo deve ser caracterizado por meio de determinações básicas utilizadas para agregado miúdo, como granulometria, massa unitária e massa específica. Para o resíduo de borracha não foi realizado ensaio de determinação de absorção devido este material não absorver quantidade de água suficiente para execução do ensaio. As características do resíduo estão mostradas na Tabela 2.

Tabela 2: Características físicas do resíduo.

\begin{tabular}{|c|c|c|}
\hline TIPO DE ENSAIO & \multicolumn{2}{|c|}{ RESULTADOS } \\
\hline \multirow{12}{*}{$\begin{array}{l}\text { Composição granulométrica } \\
\text { NBR NM } 248 \text { (ABNT, 2003) }\end{array}$} & Peneiras & Retido acumulado (\%) \\
\hline & 9,5 & 1,41 \\
\hline & 6,3 & 6,64 \\
\hline & 4,75 & 14,89 \\
\hline & 2,36 & 39,99 \\
\hline & 1,18 & 74,49 \\
\hline & 0,600 & 90,41 \\
\hline & 0,300 & 95,46 \\
\hline & 0,150 & 99,26 \\
\hline & Fundo & 100,01 \\
\hline & $\varnothing$ máx (mm) & 9,5 \\
\hline & Módulo de Finura & 4,22 \\
\hline $\begin{array}{c}\text { Massa específica }\left(\mathrm{g} / \mathrm{cm}^{3}\right) \\
\text { NBR NM } 52 \text { (ABNT, 2009), }\end{array}$ & \multicolumn{2}{|c|}{1,20} \\
\hline Massa unitária solta $\left(\mathrm{g} / \mathrm{cm}^{3}\right)$ & \multicolumn{2}{|c|}{0,34} \\
\hline
\end{tabular}




\begin{tabular}{c|c}
\hline NBR NM 45 (ABNT, 2006) & \\
\hline $\begin{array}{c}\text { Índice de volume de vazios (\%) } \\
\text { NBR NM 45 (ABNT, 2006) }\end{array}$ & 71,67 \\
\hline
\end{tabular}

Para confecção dos corpos-de-prova, os agregados foram peneirados e a areia foi mantida em estufa por 24 horas. A confecção das argamassas ocorreu de acordo com a ABNT NBR 13276 [22].

Com intuito de manter a trabalhabilidade dos diferentes traços de argamassa, fixou-se o índice de consistência ao invés da relação água/cimento. Portanto, a quantidade de água que foi acrescida à mistura foi determinada a partir do índice de consistência adotado para argamassa, que é o intervalo de (255 \pm 10$) \mathrm{mm}$, conforme referenciado por CANOVA [23].

O ensaio do índice de consistência foi realizado seguindo as diretrizes da norma ABNT NBR 13276 [21], realizado com a argamassa em estado plástico sob a mesa de fluidez. Após o ensaio de consistência foram moldados 15 corpos de prova cilíndricos, de 50x100mm, para cada subfamília de argamassa, seguindo a norma ABNT NBR 7215 [20] para moldagem de corpos de prova.

Para avaliação das argamassas em estado endurecido, os ensaios realizados foram: resistência à compressão axial, resistência à tração por compressão diametral, absorção por capilaridade, absorção por imersão e índice de vazios.

O ensaio de resistência à compressão axial foi realizado de acordo com a norma ABNT NBR 7215 [20], em duas idades da argamassa, aos 7 e aos 28 dias, e para cada idade foram rompidos três corpos-deprova de cada traço.

O ensaio de resistência à tração por compressão diametral consiste em aplicar uma carga na direção transversal do corpo de prova (geratriz), distribuindo a carga por meio de uma tira de madeira. A norma ABNT NBR 7222 [24] recomenda a utilização de tiras de chapa dura de fibra de madeira ou aglomerado. Ainda conforme apresentado na norma, as tiras de madeira foram colocadas entre o prato da máquina e o corpo de prova, sendo que foram rompidos três corpos de prova de cada traço na idade de 28 dias.

A absorção de água por capilaridade foi realizada de acordo com a norma ABNT NBR 9779 [25] em três corpos de prova de cada traço na idade de 28 dias. Foi determinada a massa saturada dos corpos de prova com idades de $3 \mathrm{~h}, 6 \mathrm{~h}, 24 \mathrm{~h}, 48 \mathrm{~h}$ e 72h, contadas a partir da colocação destes em contato com a água.

O ensaio de absorção por imersão baseou-se no procedimento da ABNT NBR 9778 [26], realizado em três corpos de prova de cada traço na idade de 28 dias. Por meio deste ensaio foi determinada a absorção, o índice de vazios e as massas específicas seca, saturada e real das amostras.

Com base no resultados obtidos nos ensaios do estado endurecido, foi realizada uma análise estatística, a qual determinou a subfamília com melhor desempenho. Por meio da subfamília definida na análise estatística foram executados dois protótipos de alvenaria, onde cada um dos protótipos foi revestido com uma argamassa diferente. Um protótipo foi revestido com a argamassa referência e o outro revestimento foi com o traço de cimento com substituição de areia por resíduo que obteve melhor desempenho nos ensaios do estado endurecido.

Para confecção dos protótipos, foram utilizados tijolos maciços nas dimensões de 9x5,3×19 cm, sendo que as dimensões finais dos protótipos foram de $70 \times 74,5 \mathrm{~cm}$. Os tijolos foram assentados e chapiscados com argamassa no traço 1:3, já no local que os protótipos ficariam expostos. Com três dias do chapisco pronto, foi realizado o taliscamento dos painéis, obedecendo a espessura do reboco de $1,5 \mathrm{~cm}$. O reboco foi realizado manualmente e foi sarrafeado e desempenado, para se obter uma superfície lisa.

Os protótipos foram expostos no ambiente externo, possuindo uma fachada voltada ao norte e a outra ao sul. Os protótipos foram executados dentro de caixas plásticas que são mantidas com nível de água de 10 $\mathrm{cm}$ no interior, com finalidade de verificar a absorção por capilaridade dos modelos. Para monitoramento do comportamento dos revestimentos, os protótipos foram fotografados sempre na mesma posição e no mesmo horário, para se manter um padrão de análise. Os primeiros sete dias foram fotografados diariamente. Após a primeira semana de exposição, os protótipos foram monitorados uma vez na semana, sempre no dia que completava sete dias do monitoramento anterior, completando 231 dias de monitoramento.

Após o período de monitoramento das manifestações patológicas foi realizado o ensaio de absorção de água pelo método cachimbo, sendo que todas as medições foram realizadas em horários que as paredes estavam sem a presença de insolação. Para cada face norte e sul de cada protótipo foram realizadas três avaliações em três pontos definidos. O CSTC prevê leituras do nível de água aos 5, 10 e 15 minutos, porém nesta pesquisa foram realizadas medidas a cada minuto ao longo de 15 minutos, conforme proposto por SELMO [27], com intuito de aumentar a precisão da curva. 


\section{RESULTADOS}

\subsection{Comportamento reológico}

Por meio do ensaio de índice de consistência se observou que com a adição de resíduo de borracha ocorreu uma diminuição no índice de consistência. Este fato pode ser observado na Figura 2, onde se constata que com o aumento da substituição de areia por borracha ocorreu um aumento na relação a/c para se manter a trabalhabilidade dentro do intervalo proposto.

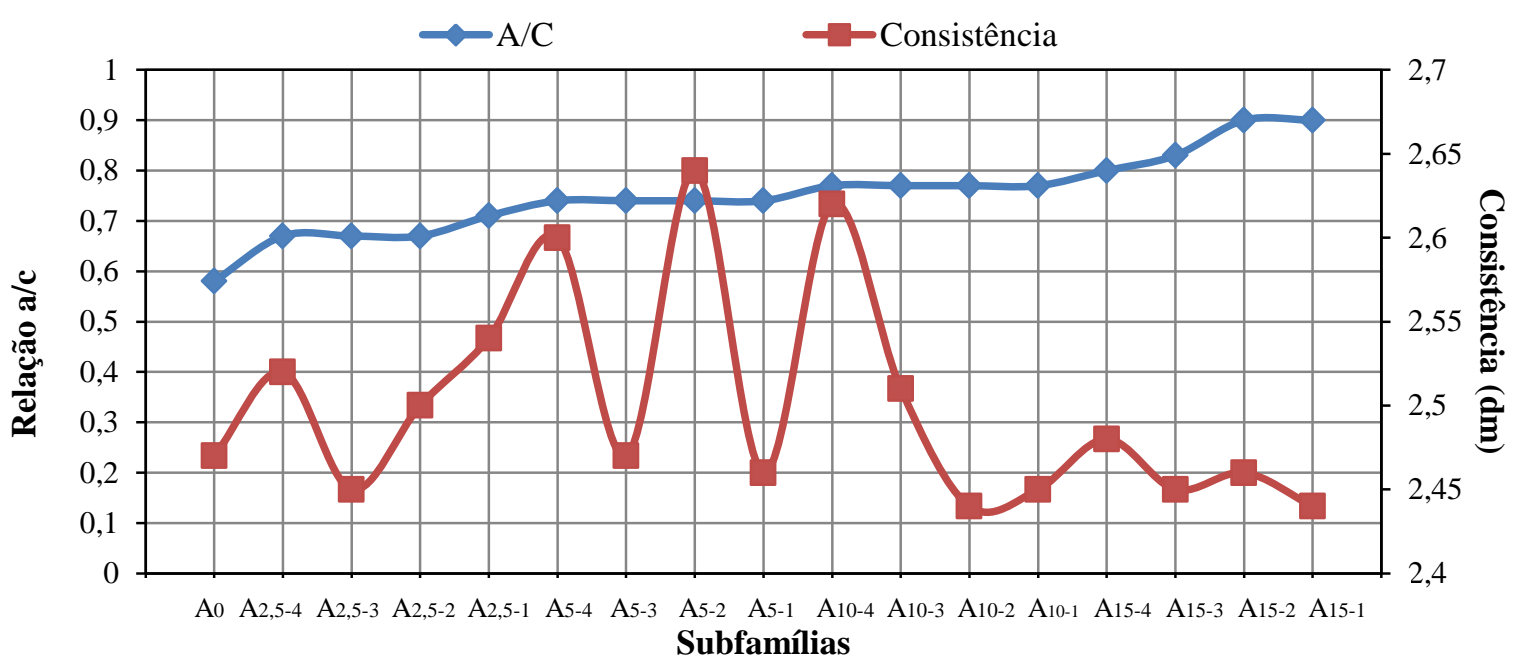

Figura 2: Relação a/c e índice de vazios das argamassas ensaiadas.

Outro fator observado é que a relação a/c aumenta para as subfamílias com menores frações de substituição. Na Figura 2, ao analisar uma família, nota-se que a que possui maior relação a/c é a com substituição de apenas uma fração, e a com menor relação é a com substituição das 4 frações. Verifica-se que, para este estudo, o resíduo de borracha atua como um material que aumenta a exigência de água para a mistura, a fim de manter a trabalhabilidade da argamassa, onde todas argamassas com utilização de resíduo apresentaram relação a/c maior que a argamassa referência.

As propriedades no estado endurecido foram estudadas por meio de ensaios de resistência à compressão axial, resistência à tração por compressão diametral, absorção por capilaridade, absorção por imersão e índice de vazios. Os resultados obtidos estão mostrados a seguir e referem-se à média dos valores obtidos para três corpos de prova para cada idade.

\subsection{Desempenho mecânico}

\subsubsection{Resistência à compressão axial}

As Figuras 3 e 4 expõem, respectivamente, os resultados obtidos para resistência de compressão axial aos 7 e aos 28 dias. Os gráficos foram divididos por família e por frações de substituição, para melhor visualização, sempre comparando com a argamassa referência (sem adição de borracha). Para uma melhor visualização dos resultados, utilizou-se nos gráficos a nomenclatura das subfamílias com um X, onde este corresponde as porcentagens de resíduos utilizados. 


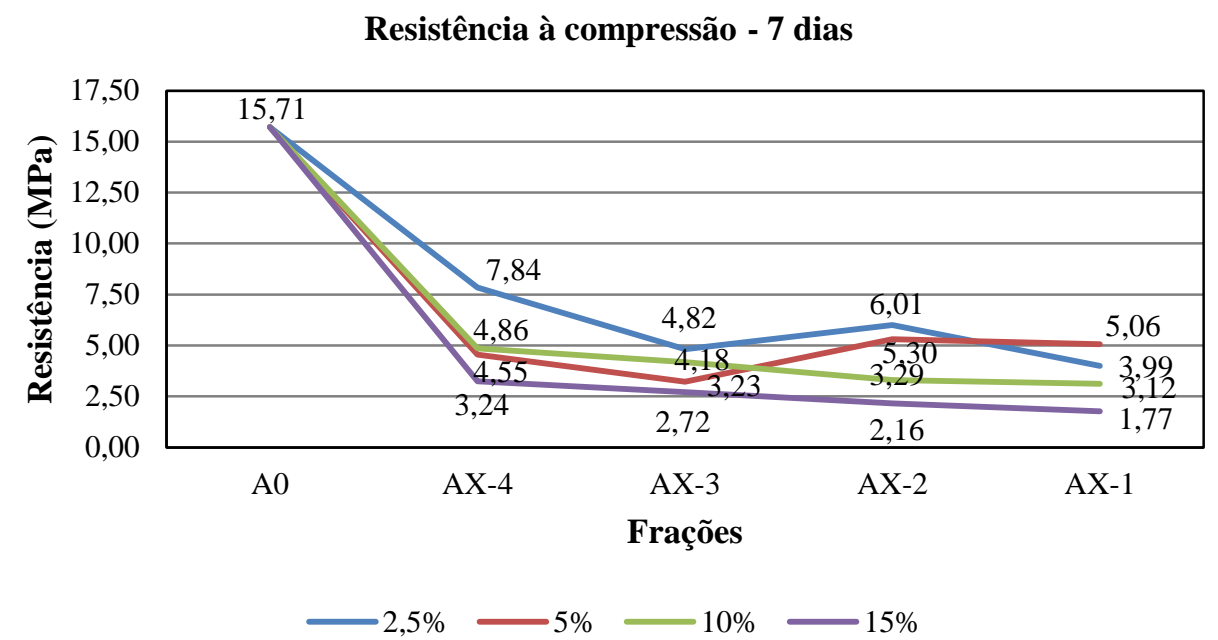

Figura 3: Resistência à compressão axial aos 7 dias.

Resistência à compressão - 28 dias

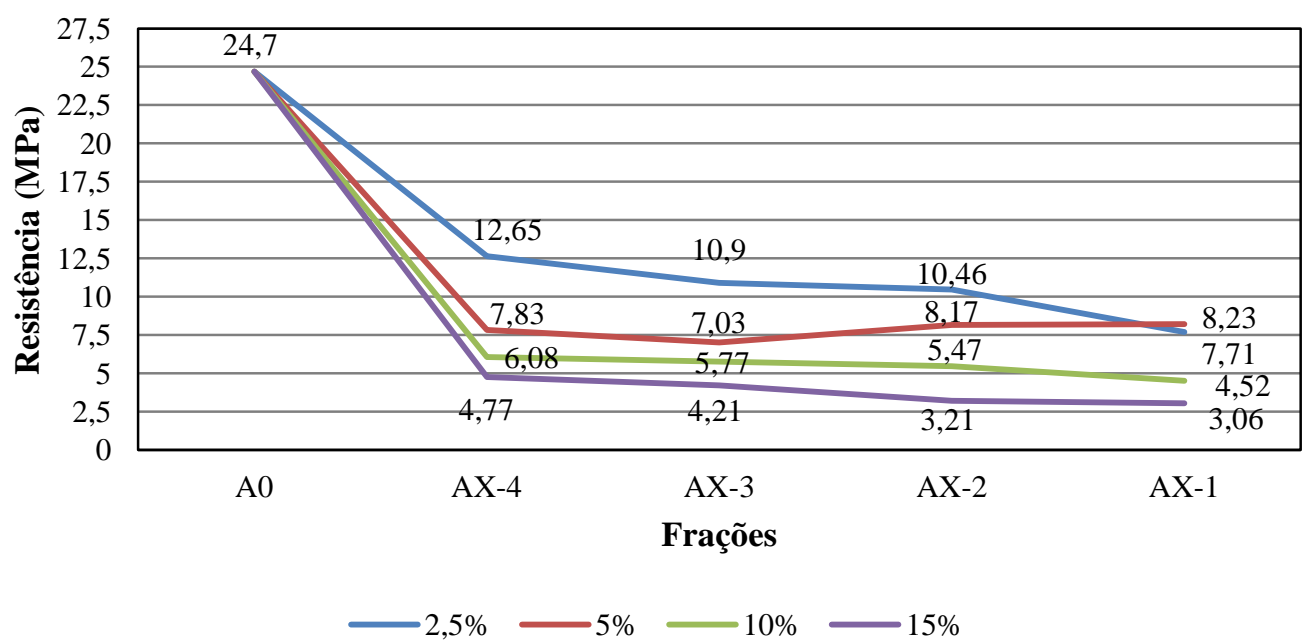

Figura 4: Resistência à compressão axial aos 28 dias.

Ao analisar os resultados mostrados nas Figuras 3 e 4, percebe-se que todas argamassas com resíduo obtiveram resistências inferiores a argamassa referência (A0). Para as argamassas com substituição, o decréscimo na resistência à compressão axial se mostra sempre mais elevado conforme o aumento na porcentagem de substituição do resíduo, sendo diferente apenas na substituição de uma fração, onde a substituição de 5\% apresenta um valor de 6,74\% superior ao da família de $2,5 \%$.

Os resultados mostram que a argamassa que possui maior decréscimo em relação a argamassa referência é a subfamília A15-1 com um decréscimo de 87,61\%, e a com menor decréscimo é a subfamília A2,5-4 com valor de $48,79 \%$.

Ao analisar os traços com melhores desempenhos quanto à resistência à compressão axial, apenas na família com substituição de $5 \%$ de areia por resíduo o melhor desempenho foi com apenas uma fração de substituição, para as demais famílias a maior resistência ocorreu na substituição das quatro frações.

A norma NBR 13281 [28] define valores mínimos de resistência à compressão axial para argamassas, e as classifica em três identificações de acordo com a resistência obtida. Classe I argamassas com resistência aos 28 dias entre 0,1 e 4,0 MPa, classe II entre 4,0 e 8,0 MPa e classe III resistência superior a 8,0 MPa. Analisando os valores resultantes dos ensaios, todas as argamassas estudadas podem ser classificadas de acordo com a norma, conforme mostrado na Tabela 3. 
Tabela 3: Classificação das argamassas de acordo com a NBR 13281:2001.

\begin{tabular}{|c|c|c|}
\hline FAMÍLIA & SUBFAMÍLIA & CLASSE \\
\hline A0 & $\mathrm{A} 0$ & III \\
\hline \multirow{4}{*}{$\mathrm{A} 2,5$} & A2,5-4 & III \\
\hline & A2,5-3 & III \\
\hline & $\mathrm{A} 2,5-2$ & III \\
\hline & A2,5-1 & II \\
\hline \multirow{4}{*}{ A5 } & A5-4 & II \\
\hline & A5-3 & II \\
\hline & A5-2 & III \\
\hline & A5-1 & III \\
\hline \multirow{4}{*}{ A10 } & A10-4 & II \\
\hline & A10-3 & II \\
\hline & A10-2 & II \\
\hline & A10-1 & II \\
\hline \multirow{4}{*}{ A15 } & A15-4 & II \\
\hline & A15-3 & II \\
\hline & A15-2 & I \\
\hline & A15-1 & I \\
\hline
\end{tabular}

De acordo com os resultados obtidos, apresentados na Tabela 3, pode-se verificar que o aumento na porcentagem de incorporação de resíduo de borracha resultou em uma diminuição na resistência à compressão axial. Este fato pode ter sido ocasionado devido a borracha ser um material com menor resistência do que a areia, e/ou pelo motivo da necessidade de uma maior adição de água para manter a trabalhabilidade.

\subsubsection{Resistência à tração por compressão diametral}

A Figura 5 apresenta os valores obtidos para a resistência à tração por compressão diametral, aos 28 dias. Os resultados demonstram que para as argamassas com substituição, o decréscimo na resistência à tração por compressão diametral se mostra sempre mais elevado conforme o aumento na porcentagem de substituição do resíduo. Porém, entre as frações substituídas não há uma continuidade no comportamento, elas variam entre as famílias, possuindo famílias (A2,5 e A15) onde o melhor comportamento está na subfamília com quatro frações substituídas, na família A5 a maior resistência a resistência à tração por compressão diametral é da subfamília com duas frações substituídas e na substituição de $10 \%$ o melhor resultado está na subfamília A10-3. Para uma melhor visualização dos resultados, utilizou-se nos gráficos a nomenclatura das subfamílias com um $\mathrm{X}$, onde este corresponde às porcentagens de resíduos utilizados. 
Resistência à tração por compressão diametral - 28 dias

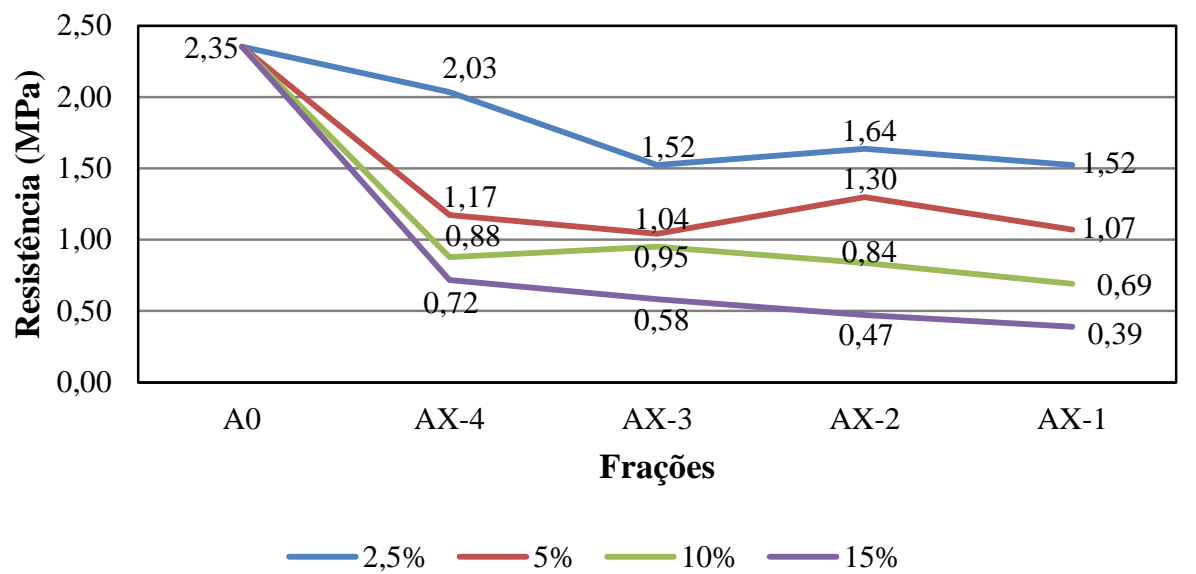

Figura 5: Resistência à tração por compressão diametral.

Os resultados mostram que a argamassa que possui maior decréscimo em relação a argamassa referência é a subfamília A15-1 com um decréscimo de 83,40\%, e a com menor decréscimo é a subfamília A2,5-4 com valor de $13,62 \%$.

Ao comparar a porcentagem de decréscimo de resistência à compressão axial e resistência à tração por compressão diametral, percebe-se que à compressão axial possui uma diminuição um pouco superior do que à tração por compressão diametral, pois ao se comparar os valores da argamassa da subfamília A2,5-4, onde ocorreu a menor diminuição de resistência em ambos os ensaios, esta possui um decréscimo de $48,79 \%$ na compressão axial e 13,62\% na tração por compressão diametral. Provavelmente este fato pode ser explicado devido à capacidade elástica do resíduo de borracha, fazendo com que ocorra menor interferência no desempenho da tração por compressão diametral.

Outro fator a ser observado é que em ambos ensaios de resistência, à compressão axial e à tração por compressão diametral, a subfamília com melhor desempenho foi a A2,5-4, podendo-se verificar que o melhor desempenho mecânico das argamassas de cimento estudadas se dá com 2,5\% de substituição de areia por resíduo nas quatro frações do agregado miúdo. $\mathrm{O}$ fato do melhor desempenho mecânico ser por meio de uma família com as quatro frações substituídas, pode ser explicado pelo fato de esta substituição possuir maior quantidade de resíduo no formato alongado, acarretando em uma maior ligação entre os componentes, pois as fibras alongadas dificultam a abertura do elemento, esta ligação pode ser visualizada na Figura 6. A presença do formato alongado estar presente somente nas subfamílias com substituição nas quatro e três frações ocorre, devido o peneiramento do resíduo, pois as peneiras utilizadas nas duas frações mais finas não propiciam a presença dos formatos alongados, apenas do pó do resíduo.

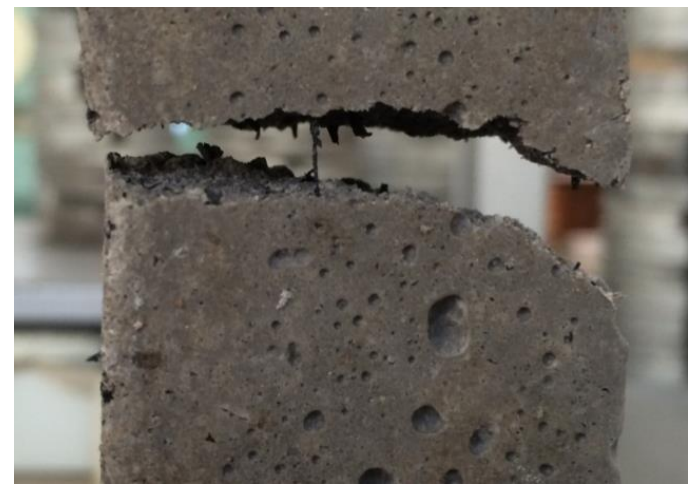

Figura 6: Argamassa com substituição nas quatro frações de agregado miúdo.

\subsubsection{Absorção por capilaridade}

A Figura 7 apresenta a absorção de água por capilaridade para as argamassas na idade de 72 horas. 


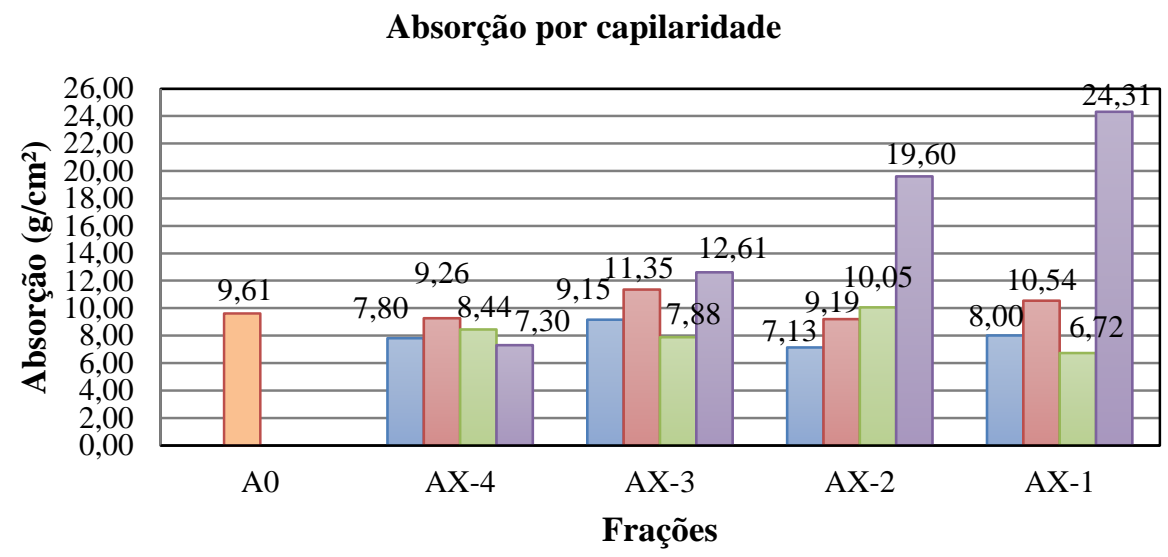

$\square 2,5 \% \quad \square 5 \% \quad \square 10 \% \quad \square 15 \%$

Figura 7: Resultados ensaio de absorção de água por capilaridade na idade de 72 horas.

Verifica-se no gráfico, que o melhor (menor absorção) e o pior desempenho (maior absorção) estão em subfamílias com apenas uma fração de substituição, sendo a menor absorção da subfamília A10-1 e a maior absorção da subfamília A15-1. Das dezesseis subfamílias com resíduo ensaiadas, apenas seis obtiveram absorção superior a argamassa referência. Ressalta-se que para as subfamílias com quatro frações substituídas, todos os traços obtiveram melhor comportamento que a argamassa sem resíduo.

Observa-se que, para família com 2,5\% de substituição, a absorção das argamassas com resíduo é menor do que a observada para argamassa referência, se tornando uma vantagem para utilização de resíduos em argamassas de revestimento. Sendo que a subfamília com melhor desempenho (menor absorção) é a A2,5-2.

Com os resultados obtidos para a família de 5\%, percebe-se que em duas frações de substituição, a com quatro e com duas frações, a absorção se mantém inferior a argamassa sem adição de resíduo, e nas outras duas substituições, com uma e com três frações, se obteve valores superiores de absorção de água. Sendo que a subfamília com melhor desempenho é a A5-2, apresentando o menor valor de absorção de água por capilaridade.

A família com $10 \%$ de substituição alcançou absorção inferior a argamassa referência em três substituições (quatro, três e uma fração), e apenas na substituição com duas frações que o valor foi superior ao da argamassa sem resíduo. Sendo que a subfamília com melhor desempenho foi a A10-1, apresentando o menor valor de absorção de água por capilaridade.

Verificando os resultados da família com $15 \%$ de substituição, observa-se que apenas a subfamília com quatro frações de substituição apresenta valor de absorção inferior ao da argamassa referência, estando as outras três subfamílias com valores superiores.

Todas as famílias de substituição possuem ao menos uma subfamília com absorção inferior a argamassa referência. Sendo uma vantagem no uso de resíduo de borracha em argamassa de revestimento, pois quanto menor a absorção de água pela argamassa melhor será seu desempenho quanto a absorção por capilaridade.

Verifica-se que a subfamília A10-1 apresenta o melhor desempenho, com uma redução de 30,07\% de absorção de água em relação a argamassa sem resíduo. Comparando-se as demais subfamílias com a A10-1, pode-se constatar que a A2,5-2 apresenta uma absorção 6,10\% maior, a A5-2 possui uma absorção 36,76\% mais elevada e a A15-4 tem uma absorção maior em 8,63\% em relação a A10-1.

\subsubsection{Absorção por imersão e índice de vazios}

A Figura 8 apresenta os valores de índice de vazios e a absorção obtida na argamassa referência e nas argamassas com resíduo. 


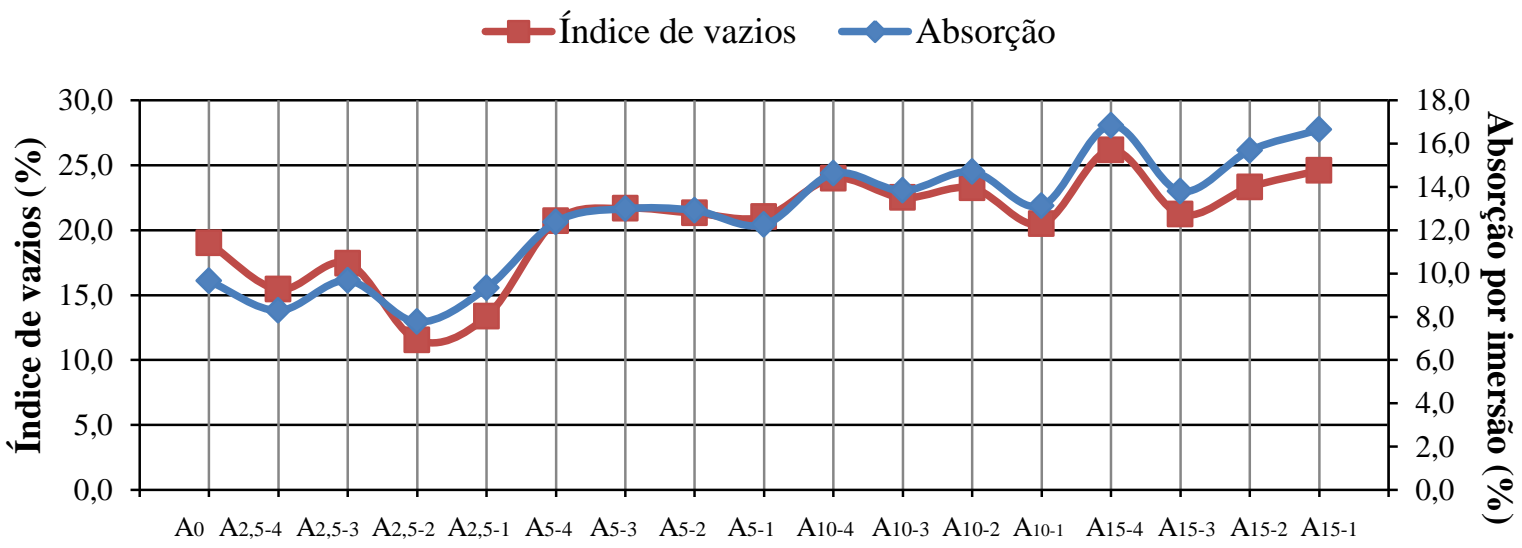

Subfamílias

Figura 8: Absorção por imersão e índice de vazios.

Conforme verificado na Figura 8, a única família que obteve absorção inferior a argamassa referência foi a com 2,5\% de substituição. As demais famílias obtiveram resultados superiores a argamassa referência, sendo que este acréscimo de absorção foi aumentando com o acréscimo de substituição de areia por resíduo de borracha, onde a família A15 apresentou os resultados com maior absorção. Analisando o melhor desempenho em relação a absorção por imersão, observa-se que o melhor foi da subfamília A2,5-2 com uma absorção 19,59\% menor quando comparada a argamassa referência. Vale ressaltar, que o traço A2,5-4 apresentou absorção pouco superior a A2,5-2, podendo ser considerada como uma subfamília com um bom desempenho.

Para os valores de índice de vazios, verifica-se que, assim como na absorção por imersão, a família A2,5 apresentou o melhor desempenho, possuindo o menor índice de vazios para todas as frações de substituição. As demais famílias obtiveram resultados superiores de índice de vazios, sendo que nas substituições de quatro, duas e uma fração o maior índice de vazios (pior desempenho) foi da família com 15\% de substituição. Sendo que na subfamília com duas frações substituídas o maior índice de vazios foi da família A10. Pode-se analisar que para família A5, independente das frações de substituição, os valores se mantiveram muito semelhantes entre si.

A Figura 9 apresenta as massas específicas determinadas através do ensaio. Ao analisar os resultados obtidos constata-se que todas as argamassas com resíduos apresentaram massa específica inferior a argamassa referência. Este fato pode ser explicado devido a borracha possuir uma massa específica real e unitária inferior a obtida pela areia, conforme mostrado nas caracterizações dos materiais. Portanto, por meio do uso de resíduo de borracha na argamassa consegue-se obter um material mais leve, caracterizado de acordo com sua massa específica em argamassa normal para uso convencional, conforme indicado por CARASECK [11].

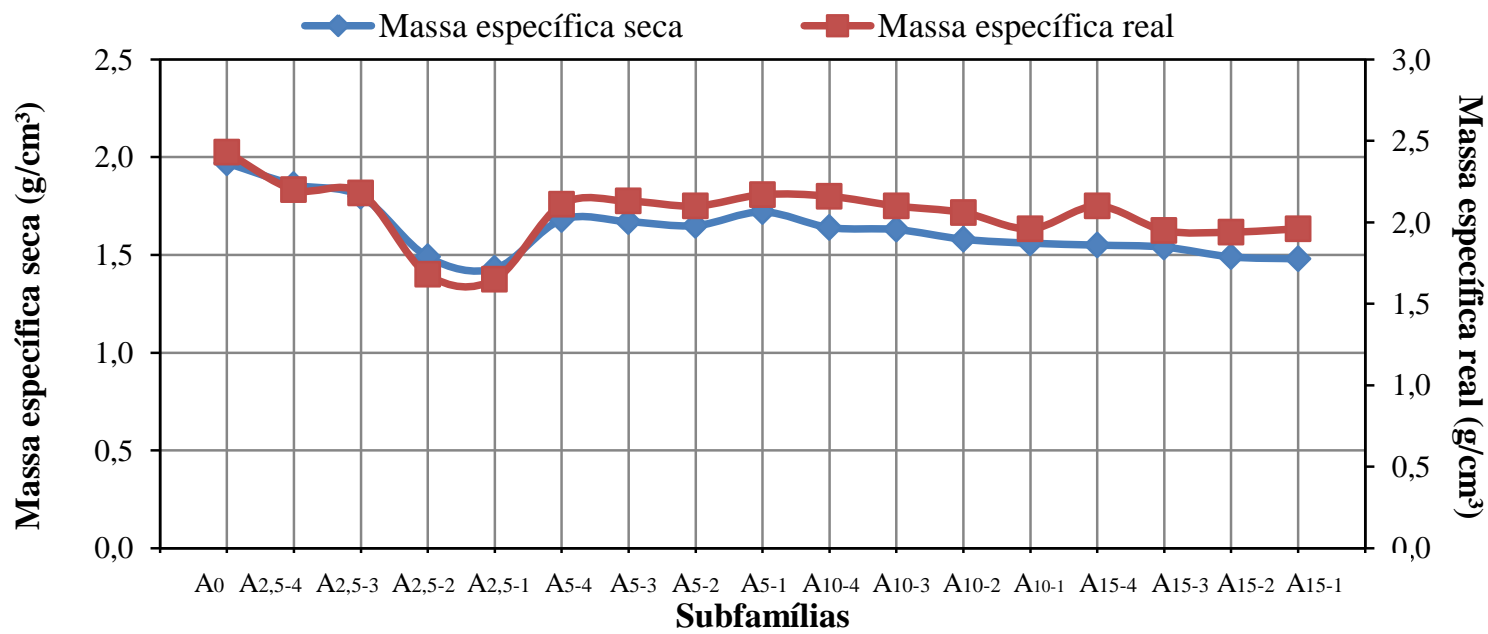

Figura 9: Massas específicas das argamassas. 
Na Tabela 4 encontra-se um resumo dos resultados obtidos nos ensaios das argamassas, tanto no estado fresco quanto no estado endurecido.

Tabela 4: Resumo dos resultados obtidos.

\begin{tabular}{|c|c|c|c|c|c|c|c|c|}
\hline SUBFAMÍLIA & $A / C$ & $\begin{array}{l}\text { CON- } \\
\text { SIST. } \\
\text { (MM) }\end{array}$ & $\begin{array}{l}\text { RESIST. } \\
\text { COMP. } \\
\text { AXIAL - } \\
28 \text { DIAS } \\
\text { (MPA) }\end{array}$ & $\begin{array}{lr}\text { RESIST. } & \dot{A} \\
\text { TRAÇÃO POR } \\
\text { COMP. DIAME- } \\
\text { TRAL - } 28 \text { DIAS } \\
\text { (MPA) }\end{array}$ & $\begin{array}{l}\text { ABS. POR } \\
\text { CAPILARI. - } \\
72 \text { HORAS } \\
\left(\mathrm{G} / \mathrm{CM}^{2}\right)\end{array}$ & $\begin{array}{l}\text { ABS. POR } \\
\text { IMERSÃO } \\
\text { (\%) }\end{array}$ & $\begin{array}{l}\text { ÍNDICE } \\
\text { DE VA- } \\
\text { ZIOS } \\
(\%)\end{array}$ & $\begin{array}{l}\text { MASSA } \\
\text { ESPECÍFI- } \\
\text { CA REAL } \\
\left(\mathbf{G} / \mathrm{CM}^{3}\right)\end{array}$ \\
\hline A0 & 0,58 & 247 & 24,7 & 2,35 & 9,61 & 9,65 & 18,99 & 2,43 \\
\hline A2,5-4 & 0,67 & 252 & 12,65 & 2,03 & 7,80 & 8,29 & 15,44 & 2,20 \\
\hline A2,5-3 & 0,67 & 245 & 10,90 & 1,52 & 9,15 & 9,67 & 17,44 & 2,18 \\
\hline A2,5-2 & 0,67 & 250 & 10,46 & 1,64 & 7,13 & 7,76 & 11,55 & 1,68 \\
\hline A2,5-1 & 0,71 & 254 & 7,71 & 1,52 & 8,00 & 9,33 & 13,36 & 1,65 \\
\hline A5-4 & 0,74 & 260 & 7,83 & 1,17 & 9,26 & 12,38 & 20,72 & 2,11 \\
\hline A5-3 & 0,74 & 247 & 7,03 & 1,04 & 11,35 & 12,99 & 21,67 & 2,13 \\
\hline A5-2 & 0,74 & 264 & 8,17 & 1,30 & 9,19 & 12,91 & 21,30 & 2,10 \\
\hline A5-1 & 0,74 & 246 & 8,23 & 1,07 & 10,54 & 12,25 & 21,01 & 2,17 \\
\hline A10-4 & 0,77 & 262 & 6,08 & 0,88 & 8,44 & 14,61 & 23,99 & 2,16 \\
\hline A10-3 & 0,77 & 251 & 5,77 & 0,95 & 7,88 & 13,82 & 22,49 & 2,10 \\
\hline A10-2 & 0,77 & 244 & 5,47 & 0,84 & 10,05 & 14,69 & 23,23 & 2,06 \\
\hline A10-1 & 0,77 & 245 & 4,2 & 0,69 & 6,72 & 13,12 & 20,47 & 1,96 \\
\hline A15-4 & 0,80 & 248 & 4,77 & 0,72 & 7,30 & 16,83 & 26,16 & 2,10 \\
\hline A15-3 & 0,83 & 245 & 4,21 & 0,58 & 12,61 & 13,79 & 21,22 & 1,95 \\
\hline A15-2 & 0,90 & 246 & 3,21 & 0,47 & 19,60 & 15,67 & 23,30 & 1,94 \\
\hline A15-1 & 0,90 & 244 & 3,06 & 0,39 & 24,31 & 16,63 & 24,59 & 1,96 \\
\hline
\end{tabular}

Por meio de análise estatística, utilizando o método ANOVA com teste F e a Análise de Componentes Principais com o programa Primer, a argamassa com melhor desempenho foi a A2,5-4.

\subsection{Protótipos de alvenaria}

A Tabela 5 apresenta os protótipos de alvenaria, os quais foram revestidos com as argamassas que apresentaram os melhores desempenhos nos ensaios do estado endurecido, no dia em que se iniciou o monitoramento dos protótipos, considerado o dia zero do monitoramento.

Tabela 5: Protótipos de alvenaria no dia Zero.

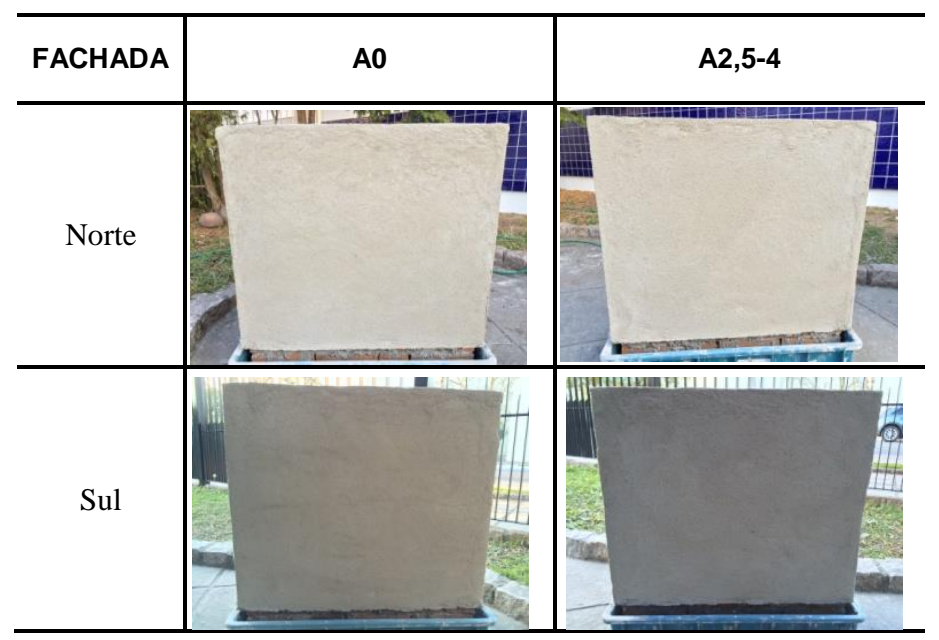


Por meio do monitoramento visual e fotográfico, com 231 dias de exposição as argamassas com resíduo de borracha não influenciaram no comportamento do revestimento argamassado, conforme mostra a Tabela 6. Este monitoramento observou os parâmetros de coloração da argamassa, crescimento ou não de micro-organismos, presença ou não de fissuras, umidade, descolamento de revestimento e demais alterações visíveis a olho nu.

Tabela 6: Protótipos de alvenaria com 231 dias de exposição.

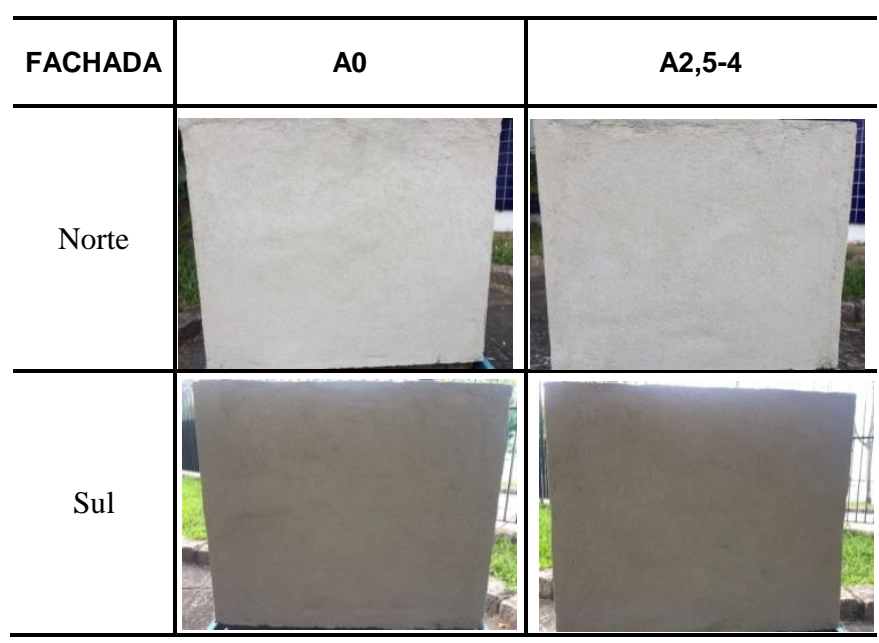

A Figura 10 apresenta a evolução da permeabilidade do revestimento das argamassas, obtidas com o ensaio do método cachimbo, sendo que é apresentada a média da absorção dos três pontos ensaiados.

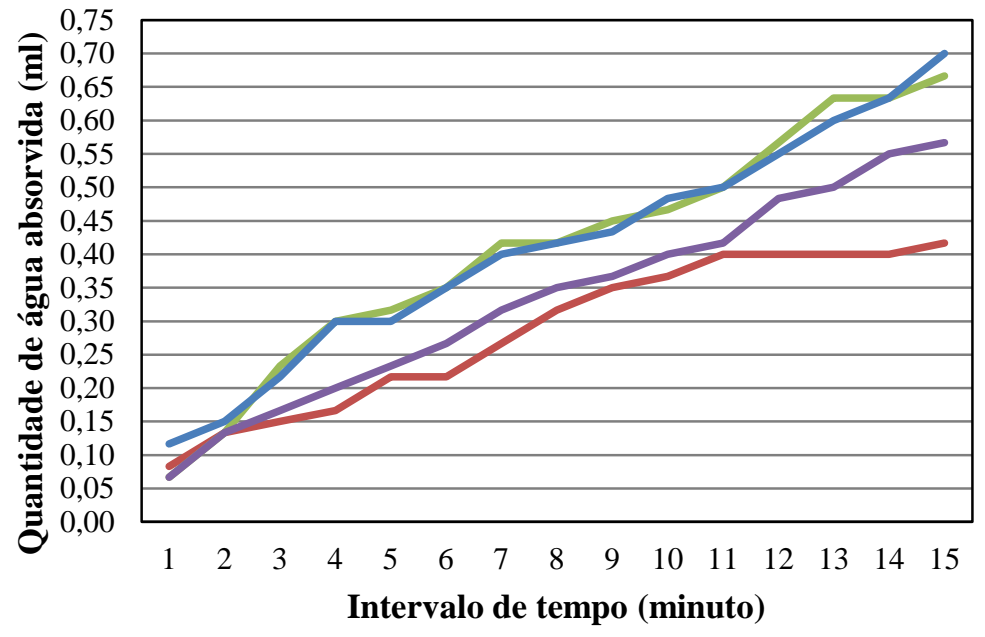

$\longrightarrow$ A0 - Norte $\longrightarrow$ A0 - Sul $\longrightarrow$ A2,5-4 - Norte $\longrightarrow$ A2,5-4 - Sul

Figura 10: Evolução da permeabilidade argamassas.

Fazendo-se uma análise dos resultados, percebe-se que na face sul ocorreu maior absorção de água em relação à face norte, em uma taxa de 37,31\% ao final dos quinze minutos. Já para argamassa A2,5-4 a face que mais absorveu água foi o lado norte, em uma porcentagem de 18,57\% ao final dos quinze minutos. Ao comparar-se as duas argamassas do traço 1:3, A0 e A2,5-4, percebe-se que a argamassa com utilização de resíduo absorveu mais água que a argamassa referência. Ao observar-se as faces que mais absorveram água, verifica-se que a A,2,5-4 absorveu 4,29\% a mais que a A0. Por meio da análise estatística obteve-se que não ocorre diferença significativa entre os resultados de absorção pelo método cachimbo para a argamassa referência e a argamassa com resíduo. 
Ao compararmos os resultados obtidos neste ensaio com o trabalho de MASSOLLA et al. [29], onde os autores utilizaram argamassa com traço 1:7 e substituição nas proporções de 10\%, 15\% e 20\%, observa-se que as argamassas com resíduo estudadas neste trabalho apresentaram absorções inferiores às apresentadas pelos autores, que obtiveram absorções no entorno de $2,5 \mathrm{ml}$ para as três argamassas com resíduo.

\section{CONCLUSÕES}

Os ensaios realizados nas argamassas demonstraram que a substituição de areia por resíduo de borracha ocasiona um aumento na relação a/c para manter a trabalhabilidade e o índice de consistência dentro do especificado, sendo que este aumento se mostra superior nas argamassas com maior substituição de areia por resíduo de borracha.

Nos ensaios de resistência à compressão axial e resistência à tração por compressão diametral, foi verificado que o aumento de incorporação de resíduo de borracha resultou em uma diminuição nas resistências, sendo que para ambos os ensaios a mistura com menor resistência foi a com maior substituição de agregado pelo resíduo de borracha. Na absorção por capilaridade todas as famílias de substituição possuem ao menos uma subfamília com absorção inferior a argamassa referência. Com vantagem para o uso de resíduo de borracha em argamassa de revestimento.

Pode-se verificar, também, que a absorção por imersão aumenta conforme aumenta a porcentagem de resíduo de borracha presente no traço, sendo que a família A2,5 resultou em uma absorção inferior a encontrada na argamassa referência.

Para os protótipos de alvenaria a utilização de borracha não influenciou o comportamento do revestimento argamassado. E no ensaio do método cachimbo pode-se verificar que a utilização de resíduo de borracha não provoca diferenças significativas no resultado de absorção de água pelo revestimento argamassado.

Por tanto, conclui-se que a utilização de resíduo de borracha em argamassas provoca mudanças de comportamento. Apesar dos valores mais baixos de resistência, seu emprego pode ser viável, pois em muitas utilizações, a resistência não é o ponto mais importante. Portanto aponta-se o uso desse resíduo em substituição ao agregado natural, como alternativa viável, tanto ambiental quanto de desempenho, pois seu uso incorporado no revestimento argamassado não apresentou mudanças visuais e mudanças de comportamento quanto à absorção de água em relação ao revestimento argamassado referência.

\section{BIBLIOGRAFIA}

[1] RECICLANIP, http://www.reciclanip.org.br/v3/quem-somos-linha-do-tempo. Acessado em março de 2016.

[2] LAGARINHOS, C. A. F., TENÓRIO, J. A. S., "Logística reversa dos pneus usados no Brasil”, Polímeros, v. 23, n. 1, pp. 49-58, São Carlos, 2013.

[3] MARQUES, A. C., Estudo da influência da adição de borracha vulcanizada em concreto à temperatura ambiente e elevada temperatura, Dissertação da M.Sc., Universidade Estadual Paulista, Ilha Solteira, 2005.

[4] LAGARINHOS, C. A. F., ESPINOSA, D. C. R., TENÓRIO, J. A. S. "Reciclagem de pneus usados no Brasil: revisão das tecnologias usadas”, In: $22^{\circ}$ CBECiMat - Congresso Brasileiro de Engenharia e Ciência dos Materiais, Natal, 2016.

[5] BEZERRA, I. M. T., Cinza da casca do arroz utilizada em argamassas de assentamento e revestimento, Dissertação do M.Sc., Universidade Federal de Campina Grande, Campina Grande, 2010.

[6] SALES, A. T. C., MENDES, J. S. S., Argamassas com agregado miúdo de resíduos de recauchutagem de pneus, In: Simpósio Internacional Em Inovação Tecnológica, 4, Anais SIMTEC, v. 1, n. 1, pp. 10-25, Aracaju, 2013.

[7] MENEGUINI, E. C. A., Comportamento de argamassas com emprego de pó de borracha, Dissertação do M.Sc., Universidade Estadual de Campinas, Campinas, 2003.

[8] CANOVA, J. A., Influência da adição de pó de borracha em argamassa de revestimento. Tese de D.Sc, Universidade Estadual de Maringá, Maringá, 2008.

[9] GÜNEYISI, E., GESÕGLU, M., ÖZTURAN, TURAN., Properties of rubberized concretes containing silica fume, Cement and Concrete Research, v.34, pp. 2309 - 2317, 2004.

[10] MARTINS, M. E., EVANGELISTA, R., ARAÚJO, J., Concreto com adição de resíduo de borracha, In: $57^{\circ}$ Congresso Brasileiro do Concreto - IBRACON, Bonito, 2015. 
[11] CARNEIRO, L. A. V., GUIMARÃES, A. C. R., SILVA, B. A., et al., Avaliação das propriedades de concreto convencional com agregados miúdos de borracha de pneus inservíveis triturados, In: $57^{\circ}$ Congresso Brasileiro do Concreto - IBRACON, Bonito, 2015.

[12] TURATSINZE, A., BONNET, S., GRANJU J. L., Mechanical characterisation of cementbased mortar incorporating rubber aggregates from recycled worn tyres, Building and Environment, p. 221-226, fev. 2005.

[13] MARQUES, A. C., AKASAKI, J. L., TRIGO, A. P. M., et al., Influence of the surface treatment of tire rubber residues added in mortars, Revista IBRACON Estruturas e Materiais, v. 1, n.2, p. 113-120, São Paulo, Jun. de 2008.

[14] PEDRO, D. A. G., VEIGA, M. R., BRITO, J., Desempenho de argamassas fabricadas com incorporação de materiais finos provenientes da trituração de pneus, In: $4^{o}$ Congresso Português de Argamassas e Etics, Coimbra, 2012.

[15] GUELMINEA, L., HADJABB, H., BENAZZOUKC, A., Effect of elevated temperatures on physical and mechanical properties of recycled rubber mortar, Construction and Building Materials, v. 126, pp. 77-85, nov. 2016.

[16] ASSOCIAÇÃO BRASILEIRA DE NORMAS TÉCNICAS, Execução de revestimento de paredes e tetos de argamassas inorgânicas - Procedimento, NBR 7200, Rio de Janeiro, 1992.

[17] SILVA, A. S. R., Argamassas: Conceitos, tipos e funções, Comunidade da construção, Salvador, 2008.

[18] CARASEK, H., Argamassas, In: Instituto Brasileiro do Concreto, Livro Materiais de Construção Civil, 2007.

[19] SOUZA, J., Estudo da durabilidade de argamassas utilizando cinzas e casca de arroz, Tese do Programa de Pós-Graduação em Engenharia de Processos, Universidade Federal de Campina Grande, Campina Grande, 2008.

[20] ASSOCIAÇÃO BRASILEIRA DE NORMAS TÉCNICAS, Determinação da resistência à compressão, NBR 7215, Rio de Janeiro, 1996. 8 p.

[21] SANTOS, A. C. dos, Avaliação do comportamento do concreto com adição de borracha obtida a partir da reciclagem de pneus com aplicação em placas pré-moldadas, Dissertação M.Sc, Universidade Federal de Alagoas, Maceió, 2005.

[22] ASSOCIAÇÃO BRASILEIRA DE NORMAS TÉCNICAS, Argamassa para assentamento e revestimento de paredes e tetos - Preparo da mistura e determinação do índice de consistência, NBR 13276, Rio de Janeiro, 3 p., 2005.

[23] CANOVA, J. A., BERGAMASCO, R., ANGELIS NETO, G., "A utilização de resíduos de pneus inservíveis em argamassa de revestimento", Acta Scientiarum Technology, v. 29, n. 2, pp. 141-149, Maringá, 2007.

[24] ASSOCIAÇÃO BRASILEIRA DE NORMAS TÉCNICAS, Determinação da resistência à tração por compressão diametral de corpos de prova cilíndricos, NBR 7222, Rio de Janeiro, 5 p., 2011.

[25] ASSOCIAÇÃO BRASILEIRA DE NORMAS TÉCNICAS, Argamassa e concreto endurecidos - Determinação da absorção de água por capilaridade, NBR 9779, Rio de Janeiro, 3 p., 2013.

[26] ASSOCIAÇÃO BRASILEIRA DE NORMAS TÉCNICAS, Argamassa e concreto endurecidos - Determinação da absorção de água, índice de vazios e massa específica, NBR 9778, Rio de Janeiro, 4 p., 2009.

[27] SELMO, S. M. S., Dosagem de cimento Portland e cal para revestimentos externos de fachadas e edificios, Dissertação de M.Sc, Escola Politécnica da Universidade Estadual de São Paulo, São Paulo, 1989.

[28] ASSOCIAÇÃO BRASILEIRA DE NORMAS TÉCNICAS, Argamassa para assentamento e revestimento de paredes e tetos - Requisitos, NBR 13281, Rio de Janeiro, 3 p., 2001.

[29] MASSOLlA, D. A. O., TORTURELI DE SÁ, M. R., VALLE, R. M. do, BASTOS, P. K. X., "Estudo do uso de resíduo de borracha proveniente da recauchutagem de pneus em argamassas de revestimento", In: Encontro Nacional de Tecnologia do Ambiente Construído - XIV ENTAC, Juiz de Fora, 2012. 